\title{
Hotspots of the sensitivity of the land surface hydrological cycle to climate change
}

\author{
HUA WenJian ${ }^{1}$, CHEN HaiShan $^{1 *}$, ZHU SiGuang $^{2}$, SUN ShanLei $^{1,3}$, YU Miao $^{1} \&$ \\ ZHOU LiMing ${ }^{4}$ \\ ${ }^{1}$ Key Laboratory of Meteorological Disaster, Ministry of Education, Nanjing University of Information Science \& Technology, \\ Nanjing 210044, China; \\ ${ }^{2}$ College of Global Change and Earth System Science, Beijing Normal University, Beijing 100875, China; \\ ${ }^{3}$ Applied Hydrometeorological Research Institute, Nanjing University of Information Science \& Technology, Nanjing 210044, China; \\ ${ }^{4}$ Department of Atmospheric and Environmental Sciences, University at Albany, State University of New York, Albany, NY 12222, USA
}

Received December 1, 2012; accepted March 4, 2013; published online May 9, 2013

\begin{abstract}
Due to the shortage of the global observational data of the terrestrial hydrological variables, the understanding of how surface hydrological processes respond to climate change is still limited. In this study, the Community Land Model (CLM4.0) with high resolution atmospheric forcing data is selected to simulate the global surface hydrological quantities during the period 1948-2006 and to investigate the spatial features of these quantities in response to climate change at the regional scales. The sensitivities of evaporation and runoff with respect to the dominant climate change factors (e.g. temperature and precipitation) derived from the concept of climate elasticity are introduced. Results show that evaporation has a declining trend with a rate of $0.7 \mathrm{~mm}$ per decade, while runoff shows a weak increasing trend of $0.15 \mathrm{~mm}$ per decade over the global land surface. Analyses of the hotspots in the hydrological cycle indicate that the spatial distributions for evaporation and runoff are similar over many areas in central Asia, Australia, and southern South America, but differ largely in high latitudes. It is also found that, the evaporation hotspots in arid regions are mainly associated with the changes in precipitation. Our sensitive analysis suggests that the hydrological quantities show a rather complicated spatial dependency of response of the water cycle to the different climate factors (temperature and precipitation).
\end{abstract}

hydrological cycle, hotspots, climate sensitivity, climate change

Citation: Hua W J, Chen H S, Zhu S G, et al. Hotspots of the sensitivity of the land surface hydrological cycle to climate change. Chin Sci Bull, 2013, 58: 36823688, doi: 10.1007/s11434-013-5846-7

The earth's climate has been warming throughout the 20th century and there is strong evidence that this warming, particularly over the last half-century, is very likely due to the increasing anthropogenic greenhouse gas concentrations [1]. One of the most direct impacts of the global warming is an accelerated hydrological cycle due to the increase of atmospheric water content associated with the warming [2]. Climate change is believed to strongly alter the global hydrological cycle $[3,4]$. A number of changes in the water cycle have been documented based on the observational studies. For example, Labat et al. [5] pointed out the global

*Corresponding author (email: haishan@ @uist.edu.cn) river flow has increased significantly during the 20th century and Roderick and Farquhar [6] found that pan evaporation has decreased in many areas of the world. Climate models also project that the frequency and intensity of extreme precipitation events will continue to increase [1]. These changes have important implications for waterresource management, agriculture, flood/drought control and many other sectors and thus the research on the changes in the global and regional water cycle has caused wide public concern all over the world.

The sensitivities of the hydrological responses to climate changes have been studied recently [7-9]. By analyzing the hydroclimate changes in the Mississippi River, Qian et al. 
[10] concluded that the increasing evapotranspiration was dominated by the changes in precipitation, whereas the impact of temperature was minor [11]. Meanwhile, the land hydrological cycle can also produce important feedbacks on the climate. For example, as one of the key land hydrological variables, soil moisture shows significant impacts on both weather and climate by altering water and energy fluxes between the land surface and the atmosphere [12-14].

Previous studies have been focused on the regional hydrological cycle based on the observations from stations. However, it is relatively difficult to explore the spatial features of the hydrological processes, especially at the global scale. Due to the shortage of a long-term and large spatial scale observed data, the land surface models can be used as an alternative tool for understanding the hydrological processes. These models can simulate important physical processes, such as energy, water and momentum fluxes that are hard to obtain directly from the observations. Therefore, it is possible and beneficial to explore the potential mechanism of hydrological variations to climate changes using land surface models. As a state-of-the-art land surface model, the Community Land Model (CLM) has been widely calibrated and evaluated at different temporal and spatial scales (e.g. using flux tower sites [15], at regional to continental scales [10]), and have been showing good performances in representing land surface processes. Particularly, compared with its previous versions, the latest one (Community Land Model version 4.0, CLM4.0) has been improved significantly [16]. Therefore, using the atmospheric forcing data from 1948 to 2006 as the inputs of CLM4.0 has the potential to provide reasonable estimate of the global hydrological quantities (e.g. runoff and evaporation).

Spatial and temporal variations in the surface hydrological variables over different regions are difficult to be accurately quantified. Recently, Giorgi [17] developed a regional climate change index (RCCI) which is an alternative approach for revealing the regional climate response. The concept of climate change hotspots can be defined as a region where climate is especially responsive to global change, which can provide the key information to identify the regional processes of climate change [17]. Using this approach, Sheng et al. [18] has investigated the hotspots of surface energy processes to the historical climate change, and $\mathrm{Xu}$ et al. [19] found that sub-regional hotspots exhibited evidently different responses to 21 st century global warming over East Asia.

In the present study, we perform the analysis of hotspots on the hydrological response to climate change based on the CLM4.0 simulations, with an emphasis on the sensitivities of hydrological response to the changes of key climate variables of temperature $(T)$ and precipitation $(P)$. The concept of climate elasticity is adopted to qualitatively evaluate the sensitivities of the hydrological quantities [20-22]. This paper starts with a brief description of the model and meth- ods in section 1 , followed by the analysis results in section 2 and the major conclusions in Section 3.

\section{Methodology}

\subsection{Model and experiment}

CLM4.0 is the latest land component within the Community Earth System Model (CESM). Compared with its previous versions, CLM4.0 incorporates significant improvements on both its physical parameterizations and model structures, including improved hydrology, snow scheme, soil dynamics and albedo parameters, together with an updated distribution scheme of various plant functional types [16]. The performance of CLM in hydrological cycle simulation has been extensively evaluated recently. Results suggest that the long-term-mean freshwater discharge into the global and individual oceans simulated by CLM is comparable to 921 river-based observational estimates [23]. Niu and Yang [24], and Niu et al. [25] evaluated the improvements of CLM3.5 in runoff treatments. Oleson et al. [26] assessed the performance of CLM3.5 and found compared results from a set of offline simulations to the observed runoff, river discharge and total water storage. More recently, Dai et al. [27] showed that the CLM3-simulated streamflow generally agrees with the observed on both the interannual and multidecadal time scales; Lawrence et al. [16] compared the global river discharge simulations with the observations [28]; Li et al. [29] used CLM4.0 to examine the runoff simulations at watershed scales. All those studies suggest that CLM has the capability to reproduce the main features of the terrestrial hydrological cycle.

The global near-surface meteorological forcing data from 1948 to 2006, which was developed by the Land Surface Hydrology Research Group at Princeton University [30], was used as the model inputs to drive CLM4.0 for our offline experiments. The forcing data was constructed by combining observations with reanalysis datasets with a temporal resolution of three hours and a horizontal resolution of $1^{\circ} \times 1^{\circ}$. The meteorological variables include humidity, longwave radiation, precipitation, shortwave radiation, surface air temperature, surface pressure and surface winds. Firstly, the model was spun up for 18 years using the forcing data of 1948 repeatedly to ensure that the deep soil moisture could reach its long-term equilibrium. Following the spin up, the simulation during 1948-2006 was performed for our following analysis.

\subsection{Definition of climate change and hydrological cycle hotspots}

To recognize the climate change hotspots, Giorgi [17] has proposed the concept of regional climate change index (RCCI) based on the change in mean value and interannual variability of temperature and precipitation. RCCI can be 
used to reflect the regional climatic responses to the global warming over selected regions. Following the work of Giorgi [17], Sheng et al. [18] quantified the index for individual energy variables such as net radiation and latent heat flux. One objective of this study is to identify the key regions where significant changes in the land surface hydrological cycle have occurred. Here we apply the concept of hotspots to explore the significance of the hydrological variations to climate change by calculating the evaporation and runoff change indexes. The change indexes of a hydrological variable $S$ is acquired by,

$$
\begin{gathered}
S_{\text {Index }}=\sum_{\text {season }}[n(\lambda S)+n(\sigma S)], \\
\lambda S=\operatorname{avg}\left(\frac{\left|S_{i, j, k}-\bar{S}_{i, j}\right|}{\bar{S}_{i, j}}\right), \\
\sigma S=\frac{S D\left(S_{i, j, k}\right)}{\bar{S}_{i, j}}
\end{gathered}
$$

where $S$ is the hydrological quantity (runoff or evaporation); $i$ and $j$ denote the meridional and zonal grid-points, respectively; $k$ is the year; $\bar{S}_{i, j}$ is the multi-year mean during the sample period for each grid box; $\lambda S$ is the multi-year mean differences between $S$ and $\bar{S}_{i, j}$ (anomaly of $S$ for each year), which quantifies the contribution of the $S$ change to the index; $\sigma S$ is defined as the standard deviation after detrending the annual time series (normalized by the 59-year climatological mean), which reflects the interannual variability of $S ; n$ is a classification coefficient, which is set to $0,1,2$, and 4 when $\lambda S$ or $\sigma S$ is $0-5 \%, 5-\% 10 \%, 10 \%-$ $15 \%$, and $>15 \%$, separately $[17,18]$. According to the definition, higher change indexes of the hydrological quantities denote the hotspots with significant changes of the corresponding hydrological variables.

\subsection{Sensitivity index of hydrological variables to climate change}

Given the linkage between the hydrological cycle and climate change, a general expression for the changes of the hydrological variables due to the variations of $T$ and $P$ can be expressed as follows,

$$
\Delta S=\frac{\partial S}{\partial T} \cdot \Delta T+\frac{\partial S}{\partial P} \cdot \Delta P,
$$

where $\Delta T$ and $\Delta P$ represent the changes in temperature and precipitation, respectively. Each hydrological variable $S$ (runoff or evaporation) is assumed to be a function of $T$ and $P$, and thus the changes in $S$ depend only on the variations of $T$ and $P . \partial S / \partial T$ and $\partial S / \partial P$ represent the contribution of changes in $T$ and $P$ to the hydrological variables, respectively.
Schaake [20] first proposed the concept of climate elasticity to evaluate the sensitivity of the streamflow to climate changes. Based on this concept, similar definitions have been widely applied for other climate variables [21,22]. In this study, the sensitivity of the hydrological variables to climate changes (e.g., $T$ and $P$ ) is defined as,

$$
\frac{\Delta S}{\bar{S}}=\alpha \cdot \frac{\Delta T}{\bar{T}}+\beta \cdot \frac{\Delta P}{\bar{P}}
$$

where $\alpha$ and $\beta$ are the sensitivity factors of the changes in $T$ and $P$, respectively. $\bar{S}, \bar{T}$ and $\bar{P}$ are the multi-year mean of variable $S, T$ and $P$, respectively. In order to emphasize the effects of the temperature and precipitation, and to separate their roles on the hydrological cycle, here we apply the similar approach to estimate the sensitivity of the hydrological quantities to climate forcing variables [11], which can be approximated as

$$
\alpha+\beta=1
$$

By combining eq. (5) with eq. (6), $\alpha$ and $\beta$ can be acquired by

$$
\begin{aligned}
& \alpha=\frac{\Delta S / \bar{S}-\Delta P / \bar{P}}{\Delta T / \bar{T}-\Delta P / \bar{P}}, \\
& \beta=\frac{\Delta S / \bar{S}-\Delta T / \bar{T}}{\Delta P / \bar{P}-\Delta T / \bar{T}} .
\end{aligned}
$$

For large sample size case, nonparametric approach can be used to estimate $\alpha$ and $\beta$ in eqs. (7a) and (7b),

$$
\begin{aligned}
& \alpha=\operatorname{median}\left(\frac{\Delta S / \bar{S}-\Delta P / \bar{P}}{\Delta T / \bar{T}-\Delta P / \bar{P}}\right), \\
& \beta=\operatorname{median}\left(\frac{\Delta S / \bar{S}-\Delta T / \bar{T}}{\Delta P / \bar{P}-\Delta T / \bar{T}}\right)
\end{aligned}
$$

and this approach has been proved to be an efficient estimator of the climate elasticity [31].

\section{Results}

\subsection{Long-term trends of global land climate and hydrological variables}

Figure 1 shows the annual anomalies of global averaged surface air temperature and precipitation rate over land excluding Antarctica. Strong variability is observed for both variables, especially precipitation. The temperature increases at a rate of $0.166^{\circ} \mathrm{C}$ per decade from 1948 to 2006, which is within the range from 0.10 to $0.16^{\circ} \mathrm{C}$ per decade during 1956 to 2005 as reported by IPCC [1]. On the other hand, the precipitation exhibits a weak downward trend (about $0.73 \mathrm{~mm}$ per decade), which is consistent with the results from Chen et al. [32]. It is noted that the variations of 


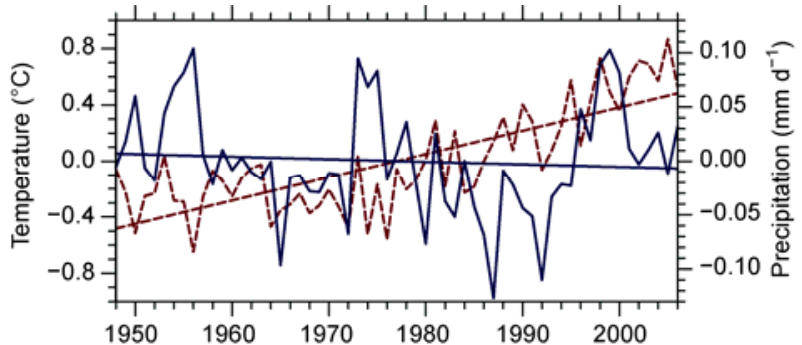

Figure 1 Anomalies of globally averaged air temperature and precipitation over land excluding Antarctica.

evaporation obtained from the offline simulations from 1948 to 2006 correlated well (the correlation coefficient of 0.552 ) with that of $P$ (Figure 2). Overall, the evaporation exhibits a declining trend with a rate of $0.7 \mathrm{~mm}$ per decade over the global land. In addition, the evaporation decreases before 1972 but increases after 1987. While the runoff shows a weak increasing trend $(0.15 \mathrm{~mm}$ per decade) over the past 59 years. We calculated correlations among the globally averaged temperature, precipitation, evaporation and runoff during the period of 1948-2006 (Table 1). It is found that the evaporation bears a significant negative correlation with the temperature but a positive correlation with the precipitation, which indicate that the global land evaporation is mainly controlled by the precipitation. Figure 3 presents the geographic distribution of the correlation between evaporation and temperature/precipitation. Evaporation shows negative correlation with the temperature in most of the global areas, while significant positive correlations between evaporation and precipitation are mainly located in arid and semi- arid regions.

\subsection{Hotspots in climate and hydrological cycle changes}

The concept of hotspots is applied to quantify and identify the regions where significant changes in terrestrial water cycle have occurred. To explore the relationships between climate changes and the hydrological cycle, Figure 4 illustrates the spatial patterns of the change index of each variable as estimated by eq. (1), with regions with higher

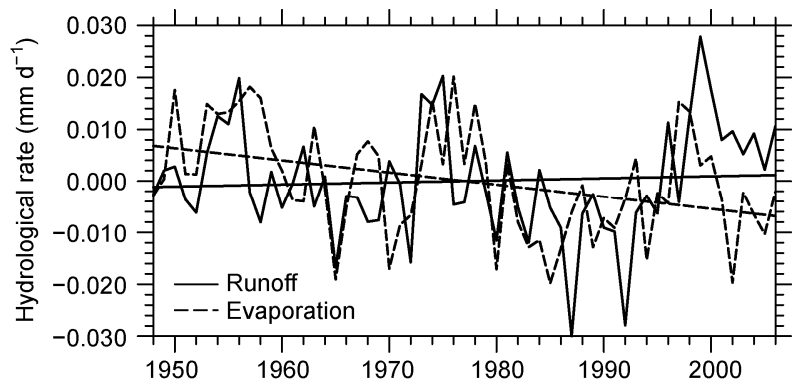

Figure 2 Anomalies for globally averaged evaporation and runoff $\left(\mathrm{mm} \mathrm{d}^{-1}\right)$ over land excluding Antarctica.

Table 1 Correlations among globally averaged temperature, precipitation, evaporation and runoff during the period of 1948-2006 ${ }^{\text {a) }}$

\begin{tabular}{cccc}
\hline & $P$ & Evaporation & Runoff \\
\hline$T$ & 0.051 & $\mathbf{- 0 . 2 7 8}$ & 0.152 \\
$P$ & & $\mathbf{0 . 5 5 2}$ & $\mathbf{0 . 9 3 4}$ \\
Evaporation & & & $\mathbf{0 . 3 1 3}$ \\
\hline
\end{tabular}

a) Values in bold are statistically significant at the 0.05 level.

indexes represent the hotspots. Compared to the climate change indexes, hotspots of $T$ (Figure 4(a)) and $P$ (Figure 4(b)) are mainly located in the higher latitudes (e.g. North America, central Siberia and Greenland) and the low latitudes (e.g. northern and southern Africa, central Asia, and Australia), respectively, indicating that these regions have relative strong response to climate changes during the past 59 years. The $P$ change indexes exhibit a similar spatial patterns to those in Sheng et al. [18], but with different magnitudes possibly due to differences in data processing methods and sample sizes (personal communication with Sheng). For the hydrological change indexes, their hotspots exhibit evidently different spatial patterns from the climate change hotspots. For example, the evaporation hotspots (Figure 4(c)) are located in central Asia, Australia and southern South America, while the runoff hotspots (Figure 4(d)) are located in central Asia, Australia, northern Africa and mid-latitude boundaries around $60{ }^{\circ} \mathrm{N}$. Additionally, comparing the change indexes of precipitation (Figure 4(b)) against those of evaporation (Figure $4(\mathrm{c})$ ), it is noted that

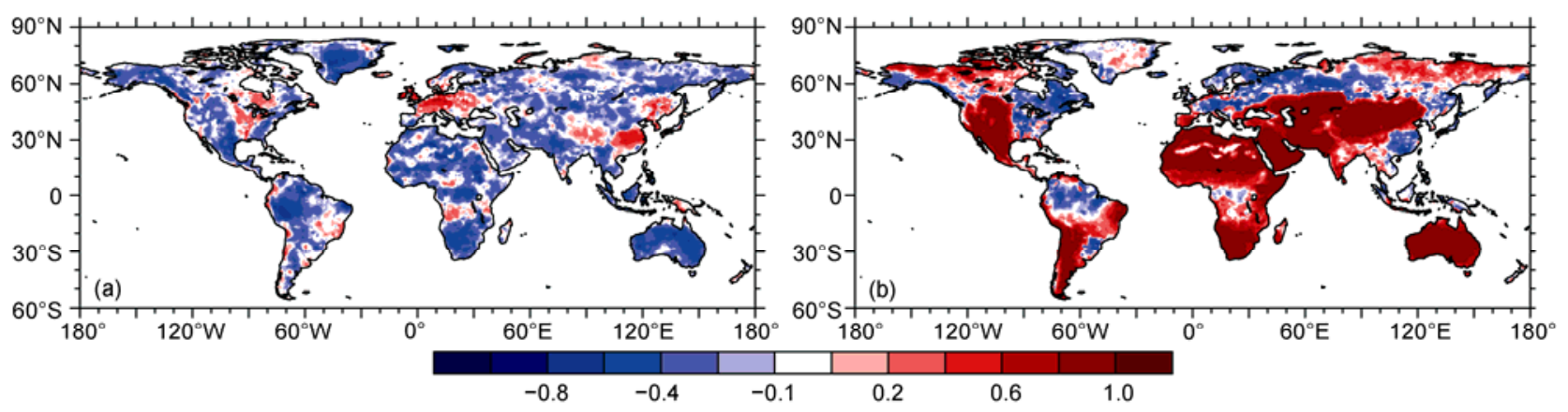

Figure 3 Spatial patterns of correlations between evaporation and (a) $T$ and (b) $P$, respectively. 


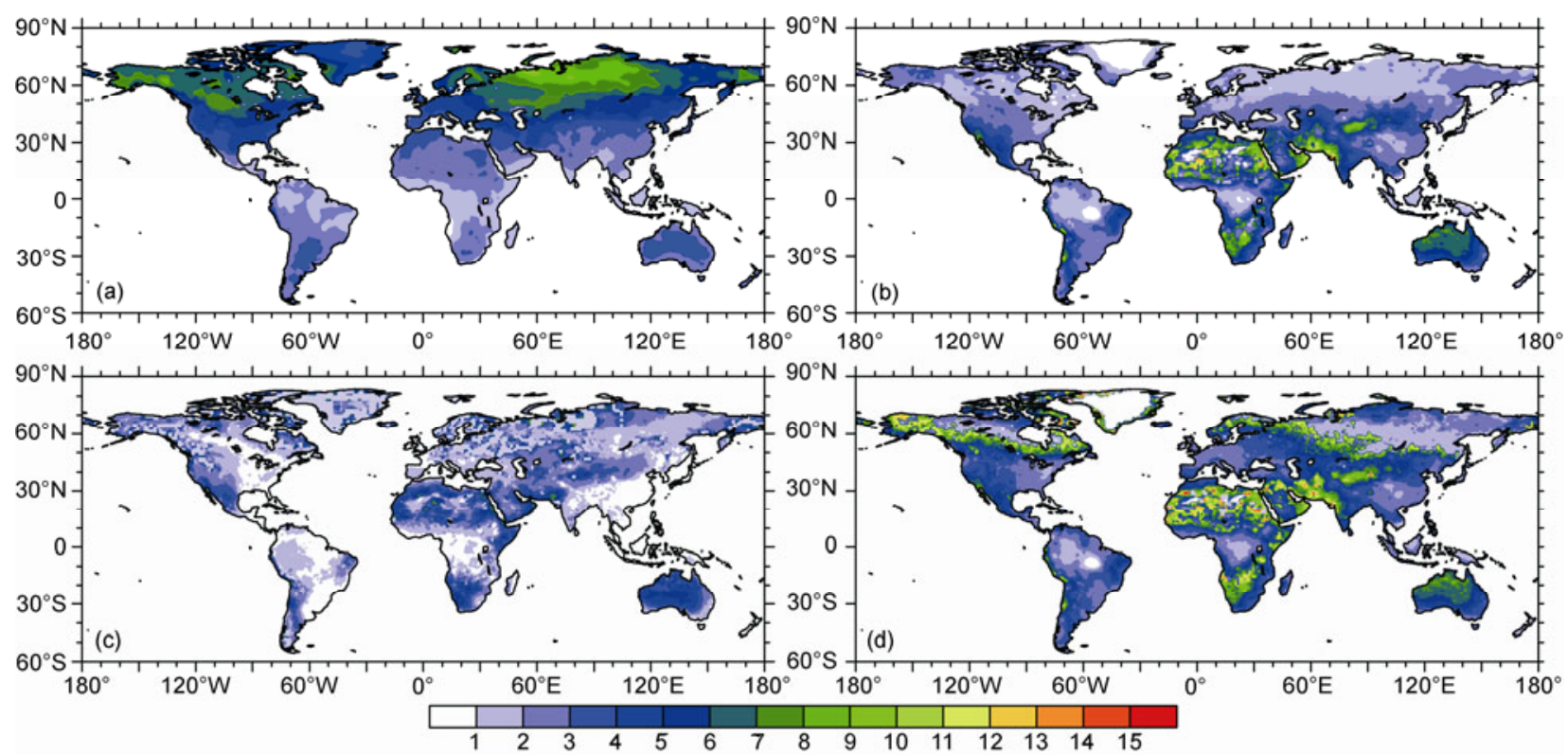

Figure 4 Regional change indexes for $T$ (a), $P$ (b), evaporation (c) and runoff over land (d). Regions with higher index values are defined as the hotspots.

the evaporation hotspots are not fully spatially associated with the $P$ hotspot, implying a high complexity of landatmosphere interactions. Moreover, it is noteworthy that the evaporation hotspots are mainly located in arid regions, which suggests that the evaporation changes are closely associated with the changes in precipitation over these regions.

\subsection{Sensitivity of the hydrological cycle to climate change}

The previous analysis in Section 2 indicates that the sensitivity of the hydrological cycle to climate change is strongly region-dependent, implying different responses at different locations. For the case of offline simulations, climate variables provide the forcing for the land surface model, and no land-atmosphere feedbacks are included. In particular, $T$ and $P$ are the most important climate forcing inputs. Given the close relationship between the changes in the water cycle and climate, next we investigate the regional scale sensitivities of hydrological quantities with respect to $T$ and $P$ using the hydrological sensitivities parameters $(\alpha$ and $\beta$ ) derived from the concept of climate elasticity.

Figure 5 presents the sensitivities of evaporation and runoff to $T$ and $P$ at each grid box excluding Greenland and Antarctica. Basically, our results inferred from the elasticity analysis are consistent with previous studies at both regional and global scales [33,34]. The evaporation elasticity to $T$ is positive on the whole, ranging from 0.7 to 1.5 over most land areas (Figure 5(a) and (b)). Its higher values are mainly located in North America, North Europe, Russia, and the northern part of South America, implying that $T$ plays a vital role in controlling the evaporation variation over these regions. However, the evaporation elasticity to $P$ exhibits evidently spatial differences with a value between -1.2 and 1.5. Its high positive values $(>0.5)$ is mainly observed in North Europe, eastern North America and Amazon basin indicating that precipitation has a closer connection to the variation of evaporation than temperature.

The elasticity of runoff to the change in $P$ is positive over most land areas, with the higher runoff elasticity values in the South America and the tropical Africa (Figure 5(d)), while the elasticity of runoff to $T$ change is mainly negative in the low latitudes but positive in the mid- and highlatitudes. Basically, higher temperatures tend to enhance evaporation, resulting in less runoff. It is also possible that the warming in the high latitudes (Figure 5(b)) has melted permafrost and reduced the seasonal snow cover, both of which could have further accelerated the water cycle. On the other hand, higher temperatures tend to increase the frequency and intensity of extreme precipitation [35], which in turn results in larger runoff.

\section{Conclusions and discussion}

Owing to the lack of the global comprehensive observations of the hydrological variables, our current understanding on the terrestrial hydrological responses to climate change is still very limited. In this study, the spatial features of the global land evaporation and runoff together with their sensitivities to climate changes during the period of 1948- 2006 are investigated based on the long-term offline simulations by CLM4.0. In order to quantify such features effectively, the concepts of hotspot and climate elasticity are introduced. Generally, the changes in climate forcing can result in evident changes in the water budgets, and the response of the hydrological cycle to individual climate variables (i.e., 

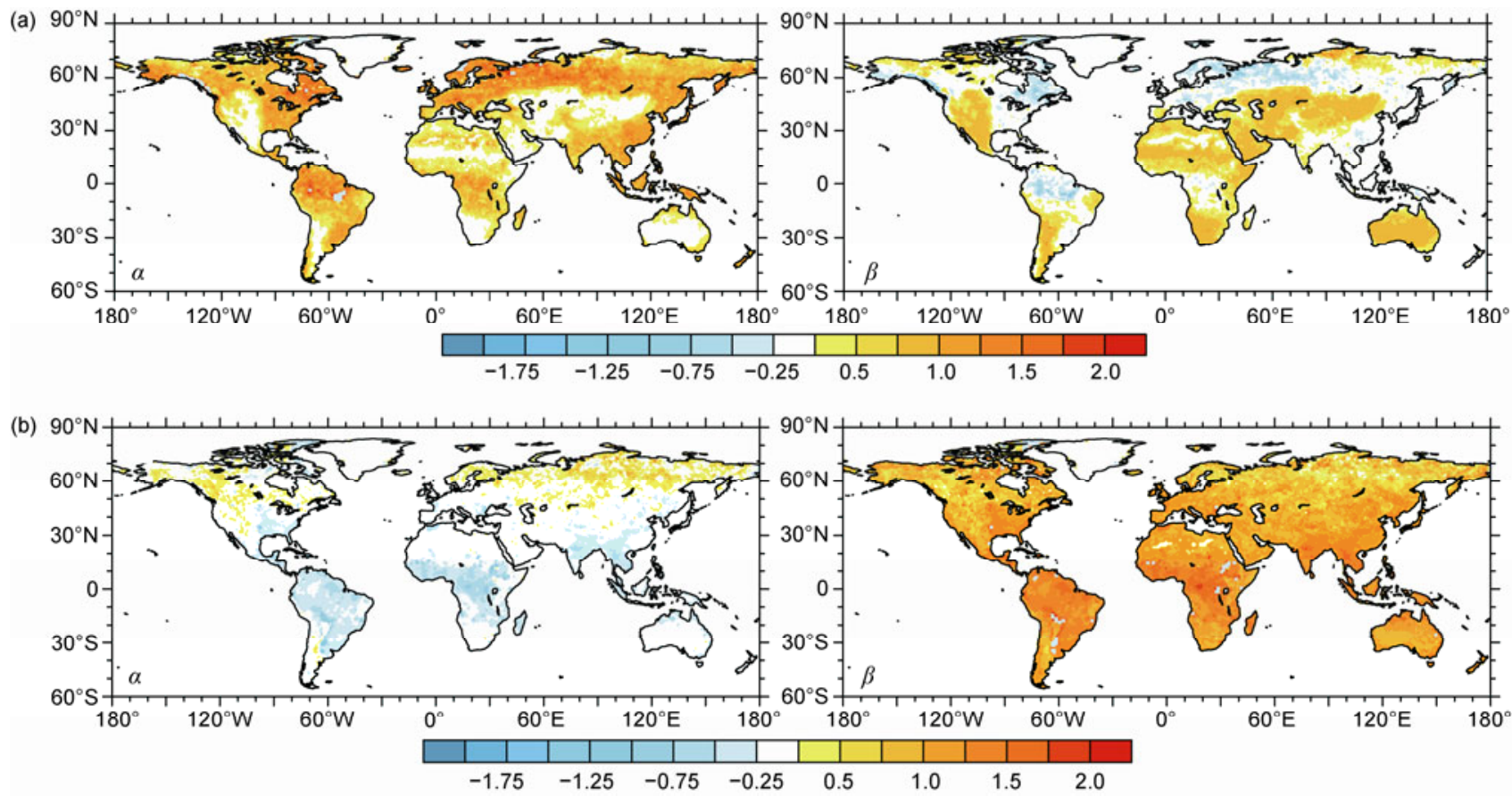

Figure 5 Contributions of $T(\alpha)$ and $P(\beta)$ to the hydrological quantities of (a) evaporation and (b) runoff over land excluding Greenland and Antarctica.

temperature and precipitation) is region-dependent and nonlinear.

The global mean evaporation over land shows a decreasing trend with a rate of $0.7 \mathrm{~mm}$ per decade, while a weak increasing trend $(0.15 \mathrm{~mm}$ per decade) is seen in runoff. Hotspots of both climate variables (temperature and precipitation) and hydrological quantities (evaporation and runoff) exhibit significant spatial variations. Basically, the regions with higher change indexes represent the hotspots, and the hydrological cycle over the hotspots is more sensitive to the climate change. For evaporation, most hotspots are located in central Asia, Australia and southern South America. The evaporative process in wet regions is generally controlled dominantly by the net radiative energy rather than by the availability of soil moisture, while the opposite is true in arid regions. Therefore, the evaporation hotspots in arid regions are mainly associated with the changes in $P$, and the runoff hotspots are similar to those of evaporation over most regions except for the high latitude areas.

It is noted that there are still some limitations and uncertainties in this study. The sensitivity analysis conducted here focused solely on the relationship between the hydrological cycle and climate change (only $T$ and $P$ were considered). Nevertheless, other climate quantities, such as solar radiation, wind speed and humidity, can also affect the hydrological cycle to some extent [6]. In addition, soil moisture also plays an important role in influencing land surface-atmosphere interactions through exchanges of energy and water fluxes. This study draws attention that most of the hydrological hotspots are located in water-limited arid and semiarid regions, where the uncertainties of the hydrological responses to precipitation are much higher [12]. During the past several decades, the land surface exhibits evident warming trends, and the effects of local warming on the hydrological cycle can not be ignored. For example the warming effects on evaporation in the high latitudes are remarkable. For some arid regions over Africa and Asia, however, evaporation seems insensitive to the changes in $P$, which needs further investigation. Furthermore, our results reported here are based on the simulations from one land surface model, and thus the use of multi-land surface model simulations will help reduce the model uncertainties. Therefore, the potential sensitivity of the hydrological cycle to climate changes remains to be further addressed in the future.

This work was supported by the Special Funds for Public Welfare of China (GYHY 201206017), the National Natural Science Foundation of China (41075082 and 41230422) and the Project Funded by the Priority Academic Program Development of Jiangsu Higher Education Institutions (PAPD). The authors thank Dr. Li Sheng for her helpful comments. Thanks also go to anonymous reviewers for their valuable comments and suggestions.

1 IPCC. Climate Change 2007: The Physical Science Basis. Contribution of Working Group I to the Fourth Assessment Report of the Intergovernmental Panel on Climate Change. Cambridge: Cambridge University Press, 2007

2 Curry R, Dickson B, Yashayaev I. A change in the freshwater balance of the Atlantic Ocean over the past four decades. Nature, 2003, 426: 826-829

3 Gedney N, Cox P M, Betts R A, et al. Detection of a direct carbon dioxide effect in continental river runoff records. Nature, 2006, 439: 835-838

4 Piao S, Friedlingstein P, Ciais P, et al. Changes in climate and land use have a larger direct impact than rising $\mathrm{CO}_{2}$ on global river runoff 
trends. Proc Natl Acad Sci USA, 2007, 104: 15242-15247

5 Labat D, Goddéris Y, Probst J L, et al. Evidence for global runoff increase related to climate warming. Adv Water Resour, 2004, 27: 631642

6 Roderick M L, Farquhar G D. The cause of decreased pan evaporation over the past 50 years. Science, 2002, 298: 1410-1411

7 Risbey J S, Entekhabi D. Observed Sacramento Basin streamflow response to precipitation and temperature changes and its relevance to climate impact studies. J Hydrol, 1996, 184: 209-223

8 Hamlet A F, Mote P W, Clark M P, et al. Effects of temperature and precipitation variability on snowpack trends in the western United States. J Clim, 2005, 18: 4545-4561

9 Wang A, Zeng X. Sensitivities of terrestrial water cycle simulations to the variations of precipitation and air temperature in China. J Geophys Res, 2011, 116: D02107

10 Qian T, Dai A, Trenberth K E. Hydroclimatic trends in the Mississippi River basin from 1948 to 2004. J Clim, 2007, 20: 4599-4614

11 Sun S, Chen $\mathrm{H}, \mathrm{Ju} \mathrm{W}$, et al. Effects of climate change on annual streamflow using climate elasticity in Poyang Lake Basin, China. Theor Appl Climatol, 2013, 112: 169-183

12 Koster R D, Dirmeyer P A, Guo Z, et al. Regional of strong coupling between soil moisture and precipitation. Science, 2004, 305: 11381140

13 Zhang J, Wang W C, Wei J. Assessing land-atmosphere coupling using soil moisture from the Global Land Data Assimilation System and observational precipitation. J Geophys Res, 2008, 113: D17119

14 Zhang R, Zuo Z. Impact of spring soil moisture on surface energy balance and summer monsoon circulation over East Asia and precipitation in East China. J Clim, 2011, 24: 3309-3322

15 Stöckli R, Lawrence D M, Niu G Y, et al. Use of FLUXNET in the Community Land Model development. J Geophys Res, 2008, 113: G01025

16 Lawrence D M, Oleson K W, Flanner M G, et al. Parameterization improvements and functional and structural advances in version 4 of the Community Land Model. J Adv Model Earth Sys, 2011, 3, doi: $10.1029 / 2011 \mathrm{MS} 000045$

17 Giorgi F. Climate change hot-spots. Geophys Res Lett, 2006, 33: L08707

18 Sheng L, Liu S H, Liu H P. Climate-induced hotspots in surface energy fluxes from 1948 to 2000. Environ Res Lett, 2010, 5, doi: $10.1088 / 1748-9326 / 5 / 1 / 014001$

$19 \mathrm{Xu} \mathrm{Y,} \mathrm{Gao} \mathrm{X,} \mathrm{Giorgi} \mathrm{F.} \mathrm{Regional} \mathrm{variability} \mathrm{of} \mathrm{climate} \mathrm{change} \mathrm{hot-}$ spots in East Asia. Adv Atmos Sci, 2009, 26: 783-792
20 Schaake J C. From Climate to Flow. In: Waggoner P E, ed. Climate Change and U.S. Water Resources. New York: John Wiley, 1990

21 Dooge J C I. Sensitivity of runoff to climate change: A Hortonian approach. Bull Am Meteorol Soc, 1992, 73: 2013-2024

22 Fu G, Charles S P, Chiew F H S. A two-parameter climate elasticity of streamflow index to assess climate change effects on annual streamflow. Water Resour Res, 2007, 43: W11419

23 Qian T, Dai A, Trenberth K E, et al. Simulation of global land surface conditions from 1948 to 2004. Part I: Forcing data and evaluations. J Hydrometeor, 2006, 7: 953-975

24 Niu G Y, Yang Z L. Effects of frozen soil on snowmelt runoff and soil water storage at a continental scale. J Hydrometeor, 2006, 7: 937-952

25 Niu G Y, Yang Z L, Dickinson R E, et al. Development of a simple groundwater model for use in climate models and evaluation with gravity recovery and climate experiment data. J Geophys Res, 2007, 112: D07103

26 Oleson K W, Niu G Y, Yang Z L, et al. Improvements to the Community Land Model and their impact on the hydrological cycle. J Geophys Res, 2008, 113: G01021

27 Dai A, Qian T, Trenberth K E, et al. Changes in continental freshwater discharge from 1948 to 2004. J Clim, 2009, 22: 2773-2792

28 Dai A, Trenberth K E. Estimates of freshwater discharge from continents: Latitudinal and seasonal variations. J Hydrometeor, 2002, 3: 660-687

29 Li H, Huang M, Wigmosta M S, et al. Evaluating runoff simulations from the Community Land Model 4.0 using observations from flux towers and a mountainous watershed. J Geophys Res, 2011, 116: D24120

30 Sheffield J, Goteti G, Wood E F. Development of a 50-year highresolution global dataset of meteorological forcings for land surface modeling. J Clim, 2006, 19: 3088-3111

31 Sankarasubramanian A, Vogel R M, Limbrunner J F. Climate elasticity of streamflow in the United States. Water Resour Res, 2001, 37 : 1771-1781

32 Chen M, Xie P, Janowiak J E, et al. Global land precipitation: A 50-yr monthly analysis based on gauge observations. J Hydrometeor, 2002, 3: 249-266

33 Chiew F H S. Estimation of rainfall elasticity of streamflow in Australia. Hydrol Sci J, 2006, 51: 613-625

34 Tang Q, Lettenmaier D P. 21st century runoff sensitivities of major global river basins. Geophys Res Lett, 2012, 39: L06403

35 Allan R P, Soden B J. Atmospheric warming and the amplification of precipitation extremes. Science, 2008, 321: 1482-1484

Open Access This article is distributed under the terms of the Creative Commons Attribution License which permits any use, distribution, and reproduction in any medium, provided the original author(s) and source are credited. 